\title{
Ultrastructure of the lung in chronic hypoxia
}

\author{
Paul Smith
}

The most striking changes in the lungs in response to prolonged alveolar hypoxia occur in the small pulmonary arteries and arterioles. The influence of chronic hypoxia on these small vessels has been subjected to extensive physiological investigation and to pathological examination by light and electron microscopy. The lung parenchyma, too, may be modified, but usually in response to brief severe hypoxia as in acute decompression or high altitude pulmonary oedema. Chronic hypoxia induces subtle changes in the lung parenchyma - for example, it has been found that the thickness of the alveolar capillary membrane of guinea pigs living at high altitude is significantly reduced compared with animals living at sea level. ${ }^{1}$ This change is so subtle, however, as to require complex morphometry of electron micrographs in order to demonstrate it. This review concentrates upon ultrastructural changes in the pulmonary arteries and arterioles, since remodelling of these vessels by hypoxia is readily appreciated by qualitative study and is of considerable practical importance.

\section{Pulmonary vasoconstriction}

Hypoxia is a potent constrictor of the pulmonary vasculature but the existence of such vasoconstriction is difficult to prove by histological criteria. A highly crenated appearance of elastic laminae in small pulmonary arteries is suggestive of constriction, but the same folding of the laminae may occur during collapse of the lung whilst it is being processed for histological examination or electron microscopy. A specific marker for vasoconstriction of the pulmonary vasculature can be seen at the ultrastructural level and was first described in rats given fulvine. ${ }^{2}$ Fulvine is a pyrrolizidine alkaloid which produces severe pulmonary arterial hypertension in rats associated with advanced pulmonary vascular disease. Electron microscopy of small pulmonary blood vessels from these rats revealed the presence of large, bulbous evaginations of the outer membrane of vascular smooth muscle cells. They were particularly numerous in pulmonary veins where the evaginations frequently herniated through the endothelial basal lamina displacing the endothelial cells into the lumen. ${ }^{2}$ Muscular evaginations were also found in small pulmonary arteries, but in this class of vessel they were largely confined to the adventitial border, herniating through gaps in the external elastic lamina. Presumably the almost continuous internal elastic lamina of the rat pulmonary artery prevented muscular evaginations from passing through it. That these evagi- nations were the direct result of vasoconstriction rather than the toxic effects of fulvine was shown by injecting normal rats with histamine. The immediate vasoconstriction which resulted was also associated with numerous evaginations of membranes of smooth muscle cells. ${ }^{2}$ This early report led to further investigations so that large pale evaginations of smooth muscle were found to be common in the pulmonary veins of rats given monocrotaline, an alkaloid related to fulvine, ${ }^{3}$ and in pulmonary veins, arteries, and muscularised arterioles in rats subjected to prolonged hypoxia. ${ }^{4}$ The latter paper was of particular interest because it showed for the first time that hypoxia can induce constriction of pulmonary veins as well as arteries. Hypoxia also promotes the formation of evaginations in the pulmonary trunk of rats where they appear as large "islands" of cytoplasm, with few organelles, situated beneath the endothelium. ${ }^{5}$ Fortuitous sections reveal that many of these apparent "islands" are connected to smooth muscle in the media by a narrow neck passing through gaps in the internal elastic lamina.

Evagination of smooth muscle is not confined to the pulmonary circulation but has been described in the aorta of hypoxic rabbits ${ }^{6}$ and in intestinal smooth muscle. ${ }^{7}$ Fay and Delise ${ }^{8}$ studied the morphological alterations in isolated smooth muscle cells from the stomach of Bufo marinus by scanning and transmission electron microscopy. They found that in the relaxed cell the surface was smooth and the myofilaments orientated longitudinally. On contraction the cell surface became covered with bulbous prominences and the myofilaments assumed a more random orientation. These evaginations of the cell membrane occurred between adjacent dark attachment points for myofilaments on the cell surface. They concluded that when the myofilaments contract they exert an inwardly directed force which squeezes out the clear cytoplasm between the attachment points to form numerous balloon-like prominences.

Although muscular evaginations are common in rats they are not seen in any form of hypertensive pulmonary vascular disease in humans described so far. ${ }^{910}$ This difference between rats and humans may simply reflect species differences. It is possible, however, that the pulmonary arteries of humans constrict to a lesser extent than those of the rat. A major component of the increased pulmonary vascular resistance associated with plexogenic pulmonary arteriopathy is therefore due to vascular occlusion by myofibroblasts rather than to vasoconstriction. ${ }^{9112}$ Furthermore, chronic hypoxia in humans is associated with a modest increase in pulmonary arterial blood pressure with mean values at rest of $29 \mathrm{~mm} \mathrm{Hg}$ in natives 
of Morococha at an altitude of $4540 \mathrm{~m} .^{13}$ This is in sharp contrast to a right ventricular mean pressure of $30-55 \mathrm{~mm} \mathrm{Hg}$ recorded in rats subjected to a pressure of $380 \mathrm{~mm} \mathrm{Hg}$ in a decompression chamber for 4-5 weeks. ${ }^{14}$

\section{Muscularisation of pulmonary arterioles} Animal species which are indigenous to high altitude, such as the llama, alpaca, mountain viscacha, and the yak, show no changes in their heart or pulmonary blood vessels in response to the hypobaric hypoxia of their environment. ${ }^{15}$ They are considered to be genetically adapted to life at high altitude. Animals which acclimatise to hypoxia have been little studied at natural high altitude except for the cow which responds with intense vasoconstriction and hypertrophy of its pulmonary arterioles. ${ }^{15}$ Instead, common laboratory animals such as rats and rabbits have mostly been studied in hypoxic chambers simulating altitudes as high as $5500 \mathrm{~m}$. This extreme hypoxia leads to severe pulmonary arterial hypertension, right ventricular hypertrophy, and pronounced muscularisation of pulmonary arterioles. ${ }^{141617}$ Humans, too, have to acclimatise to high altitude and commonly show hypoxic remodelling of the pulmonary vasculature. Arias-Stella and Saldaña ${ }^{18}$ were the first to note that pulmonary arterioles consisted of a thick media of circularly orientated smooth muscle sandwiched between two elastic laminae in Quechua Indians from Cerro de Pasco at an altitude of $4330 \mathrm{~m}$ in the Peruvian Andes. This observation was later confirmed in Aymara Indians and mestizos from $\mathrm{La} \mathrm{Paz}$ at an average altitude of $3800 \mathrm{~m}$ although only a proportion of them showed muscularised arterioles. ${ }^{1920}$ Pulmonary vascular remodelling in citizens of $\mathrm{La} \mathrm{Paz}$ may also involve the development of longitudinal muscle in the intima of small pulmonary arteries and arterioles and occasionally the formation of muscular tubes. ${ }^{20}$ Similar changes may occur in patients at sea level who develop severe alveolar hypoxia secondary to chronic obstructive airways disease. ${ }^{2122}$ The feature common to all these situations is muscularisation of pulmonary arterioles, a process involving the formation of a distinct media of smooth muscle in vessels normally devoid of muscle except at their origins. As such it has become a consistent pathological marker for chronic alveolar hypoxia.

The ultrastructure of arteriolar muscularisation has never been described in humans from high altitude, but the process has been traced in detail in the rat. The most notable change occurs about 10-14 days after rats have been living in a hypobaric chamber at a pressure of $380 \mathrm{~mm} \mathrm{Hg} .{ }^{2324}$ Plump smooth muscle cells appear between the single elastic lamina and the endothelium. These cells form an almost continuous media and many of them show features of immaturity in the form of a paucity of myofilaments confined to the periphery, with an abundance of organelles comprising rough and smooth endoplasmic reticulum, Golgi apparatus, and free ribosomes in the centre of the cytoplasm. After three weeks of hypoxia most smooth muscle cells have this immature appearance, but the quantity of myofilaments has increased. In addition, small clumps of elastin are deposited in the endothelial basal lamina. Between three and five weeks there is a progressive increase in the proportion of the cytoplasm of smooth muscle cells occupied by myofilaments with a corresponding reduction in secretory organelles. These cells now resemble mature smooth muscle. They are also encountered more frequently, suggesting either that new muscle has migrated from proximal vessels or that existing cells have undergone division. By five weeks there is an almost continuous layer of elastin beneath the endothelium forming a new internal elastic lamina.

The origin of the new smooth muscle in muscularised arterioles is far from certain. Electron microscopy of normal arterioles reveals that they contain sparsely distributed, highly attenuated smooth muscle cells immediately beneath the endothelium. ${ }^{23}$ These cells have also been referred to as pericytes and intermediate cells ${ }^{24}$ but, whatever one cares to call them, they have a muscular pedigree and presumably hypertrophy to form the immature smooth muscle during the first two weeks of hypoxia. It is likely that they can also divide since mitotic figures in pulmonary arterioles have been reported after 7-10 days of hypoxia, ${ }^{24}$ and there is uptake of tritiated thymidine by the newly formed smooth muscle. ${ }^{25}$

At the light microscopical level muscularised arterioles have a similar appearance irrespective of whether they have been induced by hypoxia or other agents. It is generally assumed, therefore, that there is but a single type of muscularised arteriole. This assumption was tested recently by comparing the ultrastructure of these vessels in rats which had been hypoxic from birth with those from young rats given the pyrrolizidine alkaloid monocrotaline. ${ }^{26}$ Both groups of animals showed extensive muscularisation of pulmonary arterioles with several layers of plump smooth muscle cells. However, smooth muscle in the hypoxic rats contained numerous fine myofilaments throughout the cytoplasm interspersed with prominent mitochondria. In rats treated with monocrotaline, on the other hand, smooth muscle cells had an immature appearance with coarse myofilaments confined to the periphery, whilst the few mitochondria and synthetic organelles occupied the central region of the cytoplasm. These qualitative impressions were confirmed by point counting electron micrographs. Of particular note was a statistically significant increase in the volume density of mitochondria and synthetic organelles in hypoxic arterioles when contrasted with those of monocrotaline-treated rats. The newly formed internal elastic lamina of the hypoxic arteriole was also thicker and more complete so that these vessels resembled minute systemic arterioles. These ultrastructural differences in smooth muscle cells suggest different functions depending on what has stimulated them, and perhaps, on the age at which that stimulus is applied. In the latter context it should be borne in mind that hypoxia from birth acts upon 


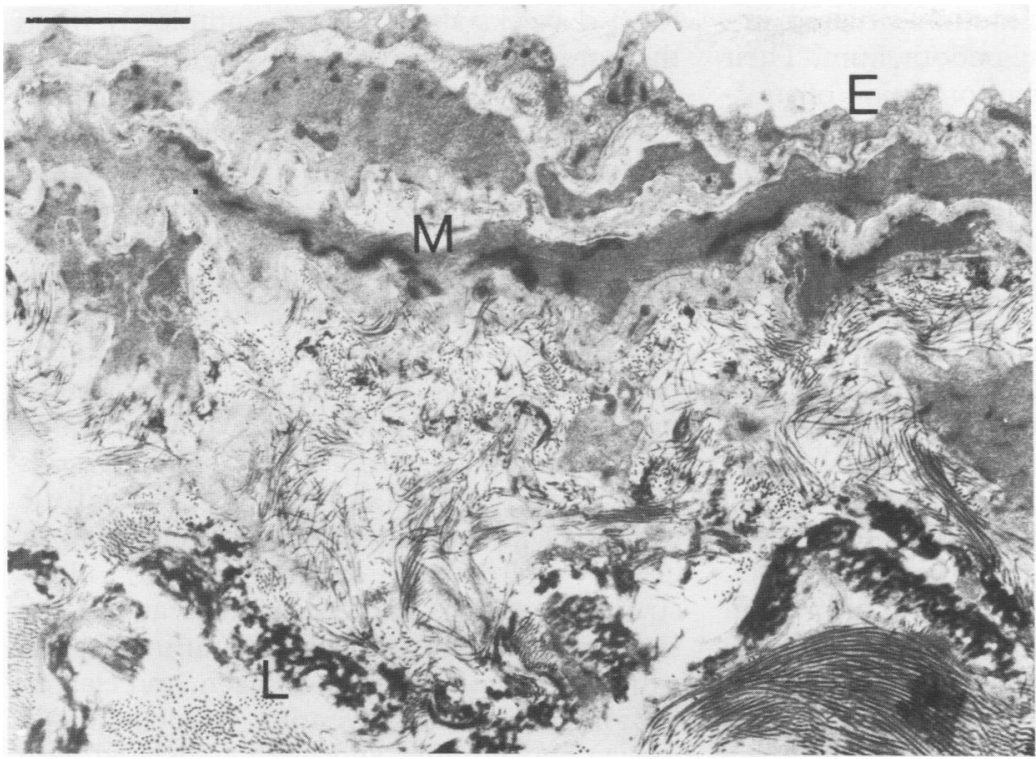

Figure 1 Part of a muscularised pulmonary arteriole from a 41 year old woman with panacinar emphysema secondary to $x_{1}$-antitrypsin deficiency. Circularly orientated smooth muscle cells (M) have accumulated between the endothelium (E) and the original, dark elastic lamina (L). In this vessel there is no newly formed internal elastic lamina. $A$ broad zone can be seen between the smooth muscle and the elastic lamina which is occupied by haphazardly arranged collagen fibrils. Bar $=2 \mu \mathrm{m}$.

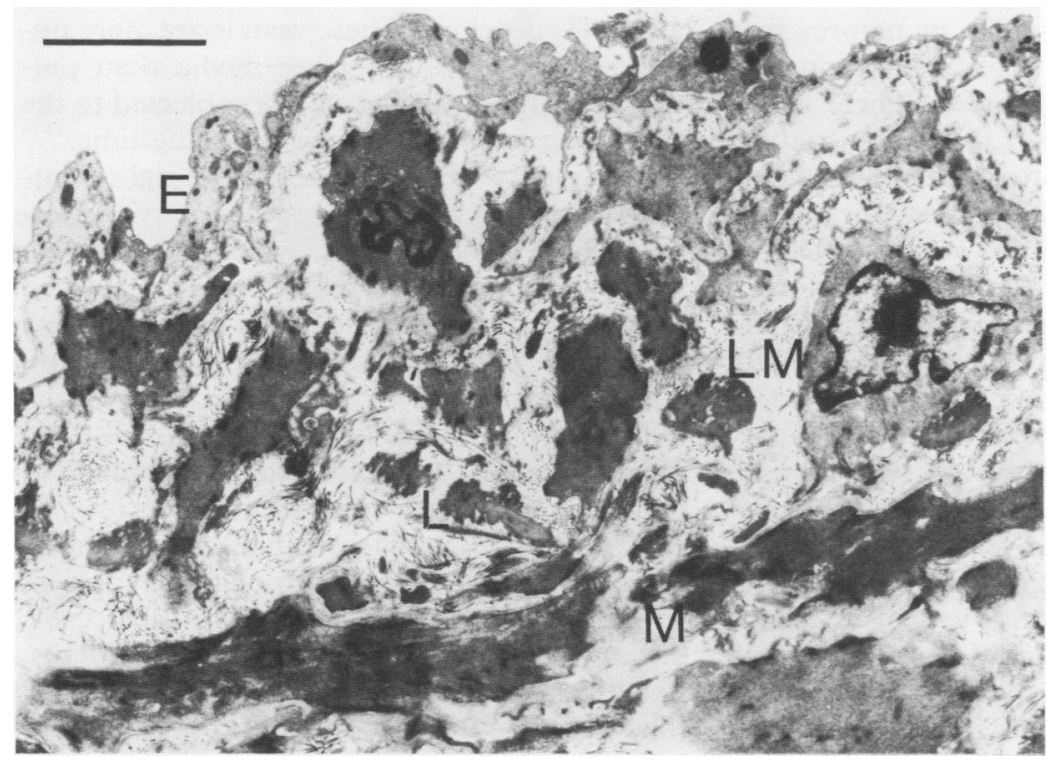

Figure 2 Transverse section of the inner region of a muscular pulmonary artery from the same patient as in fig 1. Circularly orientated smooth muscle cells of the media are shown $(M)$ with the adjacent discontinuous internal elastic lamina $(L)$. The space between the lamina and the endothelium (E) is greatly expanded by numerous smooth muscle cells with a longitudinal orientation (LM). Between these smooth muscle cells are collagen fibrils and small, darkly staining wisps of elastin. Bar $=3 \mu \mathrm{m}$.

pulmonary arterioles which retain their fetal muscular configuration and is effectively preventing the normal postnatal regression of this muscle. The increased volume density of mitochondria in smooth muscle cells of pulmonary arterioles in hypoxic rats may represent a response to an increased demand for oxidative phosphorylation in cells deprived of an adequate supply of oxygen.

Hypoxic remodelling of the pulmonary vasculature in humans

As mentioned above, there are no ultra- structural studies on the pulmonary blood vessels in humans resident at high altitude. Recently, however, we were able to obtain fresh lung tissue suitable for electron microscopy from three cases of pulmonary emphysema who had undergone combined heart-lung transplantation. ${ }^{10}$ These cases showed many of the features of remodelling of small pulmonary arteries and arterioles secondary to the alveolar hypoxia associated with chronic obstructive airways disease. Thus, one case contained numerous muscularised pulmonary arterioles, a second showed longitudinally orientated muscle in the intima of both arteries and arterioles, and the third displayed extensive intimal fibroelastosis.

At the ultrastructural level muscularised arterioles consisted of 1-3 layers of circularly orientated smooth muscle cells internal to the original elastic lamina (fig 1 ). In some arterioles the smooth muscle abutted directly onto the basal lamina of the endothelium, but in others there was a deposition of elastin beneath the endothelium to form a new, discontinuous internal elastic lamina. In this respect muscularised arterioles were similar to those in the rat but they often contained more connective tissue, particularly in a broad zone separating the external elastic lamina from the new media (fig 1). This process of muscularisation extended peripherally into the smallest of pulmonary blood vessels so that even precapillaries were surrounded by a ring of smooth muscle cells.

The earliest change in small pulmonary arteries consisted of a single layer of smooth muscle cells, orientated radially, spanning the gap between the internal elastic lamina and the endothelium. In some instances narrow "tails" of cytoplasm extended from these intimal cells, through gaps in the lamina, into the media. This appearance suggests migration of the muscle from media to intima but does not prove it. Nevertheless, there is ample evidence from other forms of pulmonary vascular disease that intimal proliferations are derived from the media. ${ }^{2728}$ In more advanced lesions the migrating smooth muscle cells adopted a longitudinal orientation with collections of them often forming pads or crescents in the intima several cells in thickness (fig 2). These smooth muscle cells were identical in structure to those in the media, and the spaces between them were occupied by collagen and discontinuous strands of elastic fibres (fig 2). The final stage consisted of an increase in quantity of connective tissue in which the elastic fibres formed a net-like pattern of anastomosing strands enclosing the muscle cells. It should be noted that, although the smooth muscle cells probably secreted the collagen and elastin, at no stage did they lose their muscular phenotype to become myofibroblasts. This is in sharp contrast to plexogenic pulmonary arteriopathy where there is a florid invasion of the intima with smooth muscle cells which then acquire numerous secretory organelles to become myofibroblasts. ${ }^{9}$

In some of the small pulmonary arteries there was a discontinuous layer of attenuated muscle 
cells with a circular orientation situated immediately subjacent to the endothelium. Their presence might explain the formation of muscular tubes in the lumens of pulmonary arteries and arterioles in some cases of emphysema or, rarely, in natives to high altitude. ${ }^{2022}$ Such tubes consist of a layer of circularly orientated smooth muscle which forms on the lumenal aspect of the intimal longitudinal muscle. This layer of smooth muscle becomes enclosed by fine elastic laminae to form a distinct tube in the intima. Although muscular tubes were not an obvious feature in the three cases described here, the subendothelial circular smooth muscle may represent an early stage in their formation. In one vessel in particular rudimentary elastic laminae were found on either side of the intimal circular muscle. The aetiology of such tubes is unclear, but they may simply be a response to haemodynamic forces since circumferential stress is greatest close to the endothelial surface of a vessel.

\section{Regression of hypoxic pulmonary vascular remodelling}

It is often assumed that, because the changes in pulmonary arterioles induced by chronic hypoxia are purely muscular in nature, they will regress completely upon restoration of a normal alveolar oxygen tension. There is evidence, however, that such regression may be incomplete. Sime et $a^{29}$ studied healthy soldiers native to Cerro de Pasco and measured their pulmonary arterial pressures at Morococha at an altitude of $4540 \mathrm{~m}$. The mean pulmonary arterial pressure was $24 \mathrm{~mm} \mathrm{Hg}$ at altitude and this fell during breathing of oxygen but did not reach the level found in natives of Lima at sea level. This partial reversal of pulmonary hypertension was attributed to relaxation of constricted pulmonary arterioles. After residence at sea level for two years the pulmonary arterial pressure in these soldiers had fallen to $12 \mathrm{~mm} \mathrm{Hg}$, a level similar to that of natives to the area. This was attributed to loss of the thick coat of muscle in the terminal arterial vessels. Sime et al noted that, despite the complete regression of pulmonary arterial hypertension at rest, these subjects showed an increase in pulmonary arterial blood pressure on exercise which was twice that of natives to Lima. This hyperreactivity of the pulmonary vasculature suggested that involution of muscularised arterioles may not be complete even after two years. Certainly, the pulmonary vascular lesions which may complicate chronic obstructive lung disease are remarkably resistant to reversal since all attempts to make them regress by long term oxygen therapy have met with singular lack of success. ${ }^{22}$ The form of pulmonary vascular disease in emphysema differs from the hypoxic remodelling at high altitude in that large quantities of collagen and elastin are secreted by intimal longitudinally orientated smooth muscle cells. Thus, a predominantly acellular, and hence irreversible, intimal fibrosis develops with the passage of time.

The pulmonary arterial hypertension which develops in adult rats subjected to $10 \%$ oxygen for 3-4 weeks also regresses completely when they are allowed to recover for five or more weeks. ${ }^{143031}$ This is associated with a gradual reduction in right ventricular weight and a loss in both the number and thickness of muscularised pulmonary arterioles. The latter process is often incomplete so that even after periods of recovery of 12 or 20 weeks there are more peripheral vessels with a distinct muscular coat than one finds in control rats. ${ }^{30-32}$ Hypoxia therefore appears to leave a prolonged imprint upon the pulmonary vasculature. This involves not only pulmonary arterioles but larger vessels also. Thus Meyrick and Reid ${ }^{33-35}$ studied the effects of prolonged hypoxia upon hilar or elastic pulmonary arteries. Their ultrastructural studies showed an increase in the size of medial muscle cells and an increase in extracellular microfibrils, collagen, and elastin. Fibroblasts in the adventitia were increased in size and number and were associated with abnormally large quantities of collagen. Upon recovery from hypoxia for 28 days the muscle cells returned to normal but much of the connective tissue persisted.

If experimental rats are born in a hypoxic chamber, or placed in one within a few days of birth, an intense muscularisation of pulmonary arterioles develops. These vessels are more numerous and have a thicker media than pulmonary arterioles of adult rats subjected to the same degree of hypoxia for the same time. ${ }^{3136}$ There is also a greater degree of right ventricular hypertrophy and pulmonary hypertension. ${ }^{3137}$ When rats which have been hypoxic during the neonatal period are allowed to recover for 12 weeks there is incomplete regression of their pulmonary hypertension, right ventricular hypertrophy, and muscularisation of pulmonary arterioles. All three parameters are in excess of those remaining in adult rats after the same period of recovery. ${ }^{31}$ At the ultrastructural level pulmonary arterioles of rats born in a hypobaric chamber possess several layers of large smooth muscle cells, each of which contain numerous myofilaments, dense attachment points, and mitochondria. ${ }^{38}$ They also have a prominent, continuous internal elastic lamina. These changes will occur after exposure for four weeks to a pressure of $490 \mathrm{~mm} \mathrm{Hg}$ simulating an altitude of $3550 \mathrm{~m}$. Despite this mild degree of hypoxia ultrastructural modifications to pulmonary arterioles are more pronounced than those of adult rats subjected to more severe hypoxia at a pressure of $380 \mathrm{~mm} \mathrm{Hg} .{ }^{23}$ During the recovery period there is no change in the vessels for the first week, but thereafter there is a progressive reduction in size and number of smooth muscle cells. After 12 weeks of recovery, however, pulmonary arterioles retain an almost continuous media of attenuated muscle cells and a distinct internal elastic lamina. ${ }^{38}$

The abnormally muscular pulmonary arterioles which persist after neonatal hypoxia should be capable of reacting rapidly and forcefully to vasoconstrictive stimuli. Such an effect has been demonstrated in rats exposed to $12 \%$ oxygen from birth for only one week and then allowed to recover for nine weeks. ${ }^{39}{ }^{40}$ When 
these animals were exposed to a further episode of hypoxia for two weeks their pulmonary vasculature responded to an acute hypoxic challenge with a greater degree of vasoconstriction than rats which had not experienced perinatal hypoxia. This suggests that perinatal hypoxia leaves a permanent structural or metabolic imprint on the small pulmonary arterial vessels rendering them hyperreactive. ${ }^{40} \mathrm{~A}$ similar conclusion was reached by Caslin et $a l^{36}$ who compared the effects of a low dose of monocrotaline on controls and rats which had experienced hypoxia for the first four weeks of their life followed by a period of recovery of 12 weeks. The control animals developed a moderate muscularisation of their pulmonary arterioles, but in the hypoxic animals these vessels were thicker and more numerous. Vessels of smaller calibre than usual were affected, indicating a shift towards the peripheral regions of the pulmonary arterial tree as in hypoxia. At the ultrastructural level these vessels showed hypertrophy and hyperplasia of the residual smooth muscle which had persisted in them from birth. ${ }^{38}$

\section{The fatal legacy}

These animal studies may have clinical significance should a similar phenomenon be found in man. Unfortunately there are no pathological reports of the long term effects of perinatal hypoxia on the pulmonary vasculature of humans, but the physiological studies of Sime et $a l^{29}$ described earlier provide circumstantial evidence that people born at high altitude retain a degree of muscularisation of their pulmonary arterioles after a prolonged residence at sea level. One can speculate that these hyperreactive pulmonary arterioles could respond to a vasoconstrictive stimulus in later life, thereby leading to pulmonary arterial hypertension. In severe cases this could progress to primary pulmonary hypertension, the pathological basis of which is plexogenic pulmonary arteriopathy. In other words, living at high altitude during the neonatal period followed by a move to sea level may leave a fatal legacy in the pulmonary vasculature which, in certain susceptible individuals, may be activated later in life to create a life threatening disease. ${ }^{36}$ Evidence for such a fatal legacy is exemplified by two intriguing case histories described below.

The first concerns a young woman who was born in the High Andes of Peru and during infancy suffered attacks of cyanosis and breathlessness. Because of these symptoms her parents brought her to the UK where she made a quick recovery which continued into adolescence. During her first year at university she became severely dyspnoeic and cardiological investigations revealed a diagnosis of primary pulmonary hypertension. She died, and sections of lung referred to this department showed gross medial hypertrophy of small pulmonary arteries with extensive acellular intimal fibrosis and the presence of plexiform lesions typical of plexogenic pulmonary arteriopathy. ${ }^{41}$ The second case was that of a Squadron Leader in the Royal Air Force who presented at the age of 34 with a history of exertional dyspnoea. $\mathrm{He}$ had a pulmonary arterial pressure at a systemic level and a diagnosis of primary pulmonary hypertension was made which required heart-lung transplantation. He was born and had lived for the first 12 years of his life in the highlands of Kenya at an altitude of $2500 \mathrm{~m}$. He then came to the UK and trained as a pilot, including repeated exposure to hypobaric hypoxia in decompression chambers. During his subsequent career he became a helicopter pilot flying at altitudes up to $4900 \mathrm{~m}$. These two cases suggest that exposure to hypoxia from birth, with subsequent reinforcement in adulthood in the latter case, may leave the pulmonary vasculature abnormally reactive and, in a minority of individuals, may lead to primary pulmonary hypertension. Further evidence comes from studies in Leadville, Colorado at an altitude of $3100 \mathrm{~m}$ where 11 cases of unexplained pulmonary hypertension have been described in children who were born there. Nine of these patients recovered after moving to sea level but two died and their pulmonary arteries showed a concentric intimal proliferation of myofibroblasts typical of the preplexiform phase of plexogenic pulmonary arteriopathy. ${ }^{42}$

The link between perinatal hypoxia and subsequent primary pulmonary hypertension is, of course, circumstantial and is based largely upon an experimental model in rats. Such comparisons between rats and humans must be made with caution since the pulmonary vasculature of the rat differs from that of humans in several respects. ${ }^{43}$ In particular, plexogenic pulmonary arteriopathy is characterised by migration of smooth muscle cells into the intima of small pulmonary arteries and arterioles, ${ }^{2844}$ a process which has never been seen in the rat. Nevertheless, the possibility of some fatal legacy imparted by perinatal hypoxia merits further investigation. Perhaps consideration should also be given to the possibility that a permanent change is retained by small pulmonary arteries and arterioles in children following corrective surgery for congenital cardiac defects. Certainly children with congenital pulmonary hypertension show an abnormal immunoreactivity for vimentin and $\alpha$-actin in their smaller pulmonary arteries. ${ }^{45}$

1 Hogan J, Smith P, Heath D, Harris P. The thickness of the alveolar capillary wall in guinea-pigs at high and low altitude. $f$ Comp Pathol 1986;96:217-26.

2 Dingemans KP, Wagenvoort CA. Ultrastructural study of contraction of pulmonary vascular smooth muscle cells. Lab Invest 1976;35:205-12.

3 Smith P, Heath D. Evagination of vascular smooth muscle cells during the early stages of Crotalaria pulmonary hypertension. F Pathol 1978;124:177-83.

4 Dingemans KP, Wagenvoort CA. Pulmonary arteries and veins in experimental hypoxia. Am $\mathcal{F}$ Pathol 1978;93 353-61.

5 Smith P, Heath D, Padula F. Evagination of smooth muscle cells in the hypoxic pulmonary trunk. Thorax 1978;33: $31-42$.

6 Kjeldsen K, Thomsen HK. Ultrastructure of the aortic intima in focal areas of intravital Evans blue uptake in the rabbit. Acta Pathol Microbiol Scand $(A)$ 1981;89:1-8.

7 Lane BP. Alterations in the cytologic detail of intestinal smooth muscle cells in various stages of contraction Cell Biol 1965;27:199-213.

8 Fay FS, Delise CM. Contraction of isolated smooth-muscle cells - structural changes. Proc Natl Acad Sci USA 1973; 70:641-5. 
9 Smith P, Heath D, Yacoub M, Madden B, Caslin A, Gosney $\mathrm{J}$. The ultrastructure of plexogenic pulmonary arterioJ. The ultrastructure of plexogenic
pathy. $f$ Pathol $1990 ; 160: 111-21$.

10 Smith P, Rodgers B, Heath D, Yacoub M. The ultrastructure of pulmonary arteries and arterioles in emphysema. $f$ Pathol 1992;167:69-75.

11 Harris $\mathrm{P}$, Heath $\mathrm{D}$. The human pulmonary circulation. Edinburgh: Churchill Livingstone, 1986:262-5.

12 Madden BP, Gosney J, Coughlan JG, Kamalvand K, Caslin AW, Smith P, et al. Clinicopathological correlation in primary pulmonary hypertension. Eur Respir $\mathcal{f} 1994 ; 7$ 672-8.

13 Peñaloza D, Sime F, Banchero N, Gamboa R, Cruz J, Marticorena E. Pulmonary hypertension in healthy men bom and living at high altitudes. Am $\mathcal{f}$ Cardiol 1963;11: 150-7.

14 Abraham AS, Kay JM, Cole RB, Pincock AC A haemodynamic and pathological study of the effect of chronic hypoxia and subsequent recovery on the heart and pul-
monary vasculature of the rat. Cardiovasc Res 1971;5: monary

15 Heath D, Williams DR. High-altitude medicine and pathology. London: Butterworths, 1989

16 Heath D, Edwards C, Winson M, Smith P. Effects on the right ventricle, pulmonary vasculature and carotid bodies of the rat of exposure to, and recovery from, simulated high altitude. Thorax 1973;28:24-8.

17 Smith P, Moosavi H, Winson M, Heath D. The influence of age and sex on the response of the right ventricle, pulmonary vasculature and carotid bodies to hypoxia in rats. F Pathol 1974;112:11-8.

18 Arias-Stella J, Saldaña $M$. The terminal portion of the pulmonary arterial tree in people native to high altitude. pulmonary arterial tree in peot

19 Heath D, Smith P, Rios-Dalenz J, Williams D, Harris P The small pulmonary arteries in some natives of $\mathrm{La} \mathrm{Paz}$ Bolivia. Thorax 1981;36:599-604.

20 Heath D, Williams D, Rios-Dalenz J, Calderon M, Gosney . Small pulmonary arterial vessels of Aymara Indians from the Bolivian Andes. Histopathology 1990;16:565-71.

21 Hicken P, Heath D, Brewer DB, Whitaker W. The smal pulmonary arteries in emphysema. 7 Pathol Bacteriol 1965; 90:107-14.

22 Wilkinson M, Langhorne CA, Heath D, Barer GR, Howard P. A pathophysiological study of 10 cases of hypoxic cor pulmonale. $Q \mathcal{F}$ Med 1986;66:65-85

23 Smith $\mathrm{P}$, Heath D. Ultrastructure of hypoxic hypertensive pulmonary vascular disease. $\mathcal{F}$ Pathol 1977;121:93-100.

24 Meyrick B, Reid L. The effect of continued hypoxia on ra pulmonary arterial circulation: an ultrastructural study. Lab Invest 1978;38:188-200.

25 Meyrick B, Reid L. Hypoxia and incorporation of ${ }^{3} \mathrm{H}-$ thymidine by cells of the rat pulmonary arteries and alveolar wall. Am f Pathol 1979;96:51-70.

26 King A, Smith P, Heath D. Ultrastructural differences between pulmonary arteriolar muscularization induced by hypoxia and monocrotaline. Exp Mol Pathol (submitted)

27 Balk AG, Dingemans KP, Wagenvoort CA. The ultrastructure of the various forms of pulmonary arterial intimal structure of the various forms of pulmonary arterial
fibrosis. Virchows Arch Pathol 1979;382:139-50.

28 Heath D, Smith P, Gosney J. Ultrastructure of early plex- ogenic

29 Sime F, Peñaza D, Ruiz L Bradycardia, increased cardiac output, and reversal of pulmonary hypertension in altitude output, and reversal of pulmonary hypertension in altitude

30 Herget J, Suggett AJ, Leach E, Barer GR. Resolution of pulmonary hypertension and other features induced by chronic hypoxia in rats during complete and intermitten normoxia. Thorax 1978;33:468-73.

31 Rabinovitch M, Gamble WJ, Miettinen OS, Reid L. Age and sex influence on pulmonary hypertension of chronic hypoxia and recovery. Am $\mathcal{f}$ Physiol 1981;240:H62-H72.

32 Leach E, Howard P, Barer GR. Resolution of hypoxic changes in the heart and pulmonary arterioles of rats during intermittent correction of hypoxia. Clin Sci Mol Med 1977;52:153-62.

33 Meyrick B, Reid L. Endothelial and subintimal changes in rat hilar pulmonary artery during recovery from hypoxia. A quantitative and ultrastructural study. Lab Invest 1980; 42:603-15.

34 Meyrick B, Reid L. Hypoxia-induced structural changes in the media and adventitia of the rat hilar pulmonary artery and their regression. Am $\mathcal{F}$ Pathol 1980;100:151-78.

35 Meyrick B, Reid L. Normal development of the media of rat hilar pulmonary artery and its remodeling by chronic hypoxia. Lab Invest 1982;46:505-14.

36 Caslin A, Heath D, Smith P. Influence of hypobaric hypoxia in infancy on the subsequent development of vasobino rat. $\mathcal{F}$ Pathol 1991;163:133-41.

37 Turek Z, Ringnalda BEM, Grandtner M, Kreuzer F. Myoglobin distribution in the heart of growing rats exposed to a simulated altitude of $3500 \mathrm{~m}$ in their youth or born in a low pressure chamber. Pflugers Arch 1973;340:1-10.

38 King A, Smith P, Heath D. Ultrastructure of rat pulmonary arterioles after neonatal exposure to hypoxia and subsequent relief and treatment with monocrotaline. $\mathcal{F}$ Pathol (submitted).

39 Herget J, Hampl V. Pulmonary vasculature of rats is influenced by perinatal experience of hypoxia. In: Widimsky $\mathrm{J}$, Herget J, eds. Pulmonary blood vessels in lung disease. Prog Respir Res 1990;26:70-6.

$40 \mathrm{Hampl}$ V, Herget J. Perinatal hypoxia increases hypoxic pulmonary vasoconstriction in adult rats recovering from chronic exposure to hypoxia. Am Rev Respir Dis 1990; 142:619-24.

41 O’Neill D, Morton R, Kennedy JA. Progressive primary pulmonary hypertension in a patient born at high altitude. Br Heart f 1981;45:725-8.

42 Khoury GH, Hawes CR. Primary pulmonary hypertension in children living at high altitude. $\mathcal{F}$ Pediatr 1963;62 177-85.

43 Heath D. The rat is a poor model for the study of human pulmonary hypertension. Cardioscience 1992;3:1-6.

44 Caslin AW, Heath D, Madden B, Yacoub M, Gosney JR, Smith P. The histopathology of 36 cases of plexogenic pulmonary arteriopathy. Histopathology 1990;16:9-19.

45 Allen KM, Howarth SG. Cytoskeletal features of immature pulmonary vascular smooth muscle cells: the influence of pulmonary vascular smooth muscle cells: the influence of 1989;158:311-7. 